\title{
Insecticide Treated Nets Usage and Barriers Among Pregnant Women Attending Ante-Natal Clinic in Ogun State, Nigeria
}

\author{
Ololade Ogunsanmi, (MPH) \\ Arit Essang, (BSc. Public Health) \\ Titilayo Olaoye, (MPH) \\ Andrew Solademi, (MSW) \\ Bose Makinde, (MSW)
}

Babcock University, Ilishan-Remo, Ogun State, Nigeria

doi: 10.19044/esj.2016.v12n30p67 URL:http://dx.doi.org/10.19044/esj.2016.v12n30p67

\begin{abstract}
Background: Malaria infection is one of the leading causes of mortality in Sub-Saharan Africa. It pose great health risks especially in pregnant women by increasing the risk of stillbirth, low birth weight and miscarriage.
\end{abstract}

Aims: The study sought to assess the level of use and the barriers to utilization of Insecticides Treated Nets (ITN) among pregnant women attending ante-natal clinics at Ikenne and Sagamu Local Government Area in Ogun State, Nigeria.

Methodology: The study employed a facility-based cross sectional design where five (5) ante-natal clinics in Ikenne and Sagamu Local Government Areas of Ogun State were visited between January and March, 2015. Three hundred and eighteen (318) pregnant women were selected through a multistage sample technique. The respondents were randomly selected on their antenatal clinic days. Data instrument was a self-administered questionnaire and verbal consent was sought from each respondent before administration. Upon retrieval of questionnaires, the data was coded, entered and analyzed with the use of the IBM SPSS version 21.

Results: Study revealed that $86.2 \%$ (274) of the respondents had used the ITN before but only $71.5 \%$ (196) of that population were currently using one. Bivariate analysis between use of ITN and marital status was statistically significant $(\mathrm{p}=0.036)$. Reported barriers to use included "net too hot" $(P=.024)$; "net not comfortable" $(P=.017)$ and "stressful to spread before bed” $(P=.190)$. 
Conclusion: There is an urgent need for further research on the barriers to sustained use and acceptability of ITNs by pregnant women.

Keywords: Malaria, pregnant women, insecticide treated nets, usage

\section{Introduction}

Malaria is caused by Plasmodium falciparum, plasmodium ovale and plasmodium vivax. Sub-Sahara Africa bears about 90\% of the global malaria burden. Malaria in Nigeria is endemic (NMCP, 2010), constitutes a major public health problem despite the curable nature of the disease and majority of Nigeria's population are at risk of the infection. In Nigeria, malaria alone accounts for $11 \%$ of maternal deaths annually (Agomo, Oyibo, Anorlu, Agomo, 2009; WHO, 2010; Obinna, 2011; Amoran, Ariba, Iyaniwura, 2012). Various researchers have reported varying prevalence rates of malaria in pregnancy in different parts of Nigeria ranging from $7.7 \%$ to $86.40 \%$ (Adefioye, Adeyeba, Hassan, Oyeniran, 2007; Kalu, Obasi, Nduka, Otuchristian, 2012; Agomo and Oyibo, 2013; Wogu and Nduka, 2013).

The groups most at risk are children under five years of age and pregnant women. Pregnant women are vulnerable because their natural immunity is reduced; thus, they are four times more likely to suffer from complications of malaria than non-pregnant women. Malaria infections especially in pregnancy are enormous public health concerns with emphasis on the risk involved for the mother as well as the fetus. The infections increase the chances of maternal deaths, pre-term or low birth weight babies as well as miscarriages (Hill, et al., 2013). Also, it has influenced increased incidence of anemia and spontaneous abortions, intrauterine growth restriction [IUGR], stillbirths, fetal distress and congenital malaria. These have placed pregnant women as a highly vulnerable group to malaria infection thus they need to be protected (Auta, 2012; Singh et al., 2013; Ankomah et al, 2012). The severity of malaria is worsened by pregnancy as a result of distinct malarial parasites that bind to the placenta. The primigravidae are more susceptible to malaria infection than multigravidae, because the former are still in the process of acquiring natural immunity to placental malaria.

The World Health Organization (WHO) recommends the use of Insecticide treated nets (ITNs) which serve as a powerful public health tool in preventing malaria when used appropriately. These nets are highly beneficial to the health of the developing child as they have been shown to be the most cost effective measures in the prevention of malaria (WHO, 2008; Lengeler, 2004). Apart from reducing infant mortality, it reduces risk of low birth weight infants and premature delivery. Even though untreated nets provide protection, ITNs are approximately twice as effective and offer 
over 70\% protection when compared with no nets (Clarke et al., 2001; D'Alessandro et al., 1995). A number of studies have demonstrated that the use of ITNs is very effective in controlling malaria and therefore reducing malaria-related mortality (D’Alessandro et al., 1995; Hawley et al., 2003; Huailu et al., 1995). ITNs were introduced in Nigeria as an effective means of preventing mosquito bites and malaria transmission following the meeting of African Heads of States in Abuja, Nigeria in the year 2000 (RBM, 2010). Malaria control intervention such as possession and utilization of ITNs are geared towards building institutional and human resources to fight the malaria scourge.

Although there have been evidence of ITNs reducing malaria-related morbidities, barriers and challenges have been recorded to the utilization and acceptance of these nets. The study therefore was carried out to determine the level of usage and the barriers to the utilization of the insecticide treated nets among pregnant women in Ogun State.

\section{Research questions} Ogun State?

1. What is the level of usage of ITNs among pregnant women in

2. What difference does the respondents' level of education have on their usage of insecticide treated nets?

3. What influence does the pregnant women's marital status have on their usage of insecticide treated nets?

4. What are the barriers to the usage of insecticide treated nets among pregnant women?

5. Is there a statistical relationship between the reported barriers to usage and the actual usage of ITNs?

\section{Materials and methods}

The study was facility based and cross sectional in design. The target population was pregnant women attending ante-natal clinics in Sagamu and Ikenne Local Government Areas (LGAs) in Ogun State Nigeria. Multi-stage sampling technique was used in selecting five (5) health facilities in the LGAs. Stage 1: Two (2) local governments were purposefully selected from the 20 local governments in Ogun State (Ikenne \& Sagamu). Stage 2: Cluster random sampling technique was used to select one (1) ward in Ikenne local government (Ilishan Remo) two (2) wards from Sagamu local government (Sabo \& Makun). Stage 3: Convenient sampling technique was used to select all the health facilities in Ikenne LGA (3); Babcock University Teaching Hospital, Community Hospital Ilishan-Remo and Ikenne local government health clinic, Ilishan Remo while two (2) were selected randomly (balloting) from Sagamu LGA: Health Clinic Sagamu LGA, Agura Sabo and Sagamu 
LGA Primary Health Centre, Ajaka, Makun. Proportionate sampling technique was used to distribute questionnaire to the five health facilities based on their population. Three hundred and eighteen (318) pregnant women were purposively recruited. On the day of visit, women present in the Ante-natal clinic were randomly selected (balloting) and the questionnaires was administered to them. Data was gathered with the use of a selfadministered open and closed ended questionnaire which measured sociodemographic characteristics, utilization of ITNs and factors affecting net use. Verbal consent was obtained from each respondent before administration of the questionnaires and they were informed of the purpose of the study and given guidelines regarding filling correct information in the questionnaire. Respondents who were illiterate had the data instrument explained by research assistants. The research assistants translated and aided respondents who were not literate in administering their questionnaire. The data collected was coded and the use of the IBM SPSS version 21 was employed for entry and analysis. Results were presented in frequency tables and regression was employed for presentation of results.

\section{Results}

Most of the respondents were between the ages of 20 to 29 and Christians. Over two-thirds were married from the Yoruba tribe. Over half of the respondents reported to have a tertiary level of education while a third were traders.

Table 1: Socio-demographic distribution of respondents

\begin{tabular}{|c|c|c|c|}
\hline \multicolumn{2}{|c|}{ VARIABLES } & $\begin{array}{c}\text { FREQ } \\
(\mathrm{n}=318)\end{array}$ & PER (\%) \\
\hline \multirow{2}{*}{ Age } & $15-19 \mathrm{yrs}$ & 29 & 9.1 \\
\hline & $20-24 \mathrm{yrs}$ & 103 & 32.4 \\
\cline { 2 - 4 } & $25-29 \mathrm{yrs}$ & 109 & 34.3 \\
\cline { 2 - 4 } & $30-34 \mathrm{yrs}$ & 42 & 13.2 \\
\cline { 2 - 4 } & 35yrs and above & 35 & 11.0 \\
\hline Marital status & Single & 101 & 31.8 \\
\hline & Married & 217 & 68.2 \\
\hline & & & \\
\hline Religion & Christianity & 242 & 76.1 \\
\hline & Islam & 72 & 22.6 \\
\hline & Traditional & 4 & 1.3 \\
\hline & & & \\
\hline & Yoruba & 212 & 66.7 \\
\hline Ethnicity & Igbo & 54 & 17.0 \\
\hline & Hausa & 23 & 7.2 \\
\hline & Others & 29 & 9.1 \\
\hline Level of education & & & \\
\hline & Primary & 33 & 10.4 \\
\hline & Secondary & 99 & 31.1 \\
\hline
\end{tabular}




\begin{tabular}{|c|c|c|c|}
\hline & Tertiary & 168 & 52.8 \\
\hline & No formal education & 17 & 5.3 \\
\hline & Others & 1 & 0.3 \\
\hline & & & \\
\hline & Unemployed & 20 & 6.3 \\
\hline Occupation & Trading & 107 & 33.6 \\
\hline & Students & 58 & 18.2 \\
\hline & Fashion Designer & 6 & 1.9 \\
\hline & Caterer & 11 & 3.5 \\
\hline & Tailoring & 9 & 2.8 \\
\hline & Housewife & 11 & 3.5 \\
\hline & Accountant & 21 & 6.6 \\
\hline & Teaching & 33 & 10.4 \\
\hline & Matron & 11 & 3.5 \\
\hline & Secretary & 2 & 0.6 \\
\hline & Nursing & 9 & 2.8 \\
\hline & Hairdresser & 13 & 4.1 \\
\hline & Cleaner & 6 & 1.9 \\
\hline & Pastor/Church worker & 1 & 0.3 \\
\hline & & & \\
\hline & First Trimester & 94 & 29.6 \\
\hline & Second Trimester & 161 & 50.6 \\
\hline & Third Trimester & 54 & 17.0 \\
\hline & I don't know & 9 & 2.8 \\
\hline
\end{tabular}

Results revealed that over eighty percent of the respondents (274; 86.2\%) had used insecticide treated nets before at different times and $71.5 \%$ (196) of this proportion was currently using one. Asides from themselves, 199 (72.6\%) of the respondents who had used these nets before revealed that their children and the whole family make use of these nets also.

Table 2: Summary of Frequency Distribution of Respondents' Use of Insecticide ${ }^{* *} \mathrm{n}=274$

\begin{tabular}{|c|c|c|}
\hline Variable & $\mathrm{N}$ & $\%$ \\
\hline Ever used Insecticide treated nets? & 274 & 86.16 \\
Yes & 44 & 13.84 \\
No & $196^{* *}$ & 71.53 \\
\hline Currently using an insecticide treated net & $199^{* *}$ & 72.63 \\
\hline
\end{tabular}

Respondents' marital status significantly had an influence on their use of ITNs. This result shows that been in a marriage can influence the use of ITNs among pregnant women and this directly translates to improvement on the health and wellbeing of the women and their unborn children. 
Table 3: Summary of Bivariate Analysis between Respondents’ Level of Education and Use of Insecticide Treated Nets

\begin{tabular}{|c|c|c|c|c|}
\hline Age & \multicolumn{2}{|c|}{ Use of insecticide treated nets } & \multirow[t]{2}{*}{ Total } & \multirow[t]{2}{*}{$\mathrm{x}^{2} ; \mathrm{p}$-value } \\
\hline & Yes & No & & \\
\hline $15-19$ & 22 & 7 & 29 & \multirow{5}{*}{$.407 ; .102$} \\
\hline $20-24$ & 87 & 16 & 103 & \\
\hline $25-29$ & 96 & 13 & 109 & \\
\hline $30-34$ & 38 & 4 & 42 & \\
\hline 35 and above & 31 & 4 & 35 & \\
\hline Total & 274 & 44 & 318 & \\
\hline Level of Education & \multicolumn{2}{|c|}{ Use of insecticide treated nets } & & \multirow{5}{*}{$.471 ; .061$} \\
\hline Primary & 26 & 7 & 33 & \\
\hline Secondary & 83 & 16 & 99 & \\
\hline Tertiary & 148 & 20 & 168 & \\
\hline No formal education & 17 & 1 & 18 & \\
\hline Total & 274 & 44 & 318 & \\
\hline Marital Status & \multicolumn{2}{|c|}{ Use of insecticide treated nets } & & \multirow{4}{*}{$.036 ; .036$} \\
\hline & Yes & No & & \\
\hline Single & 81 & 20 & 101 & \\
\hline Married & 193 & 24 & 217 & \\
\hline Total & 274 & 44 & 318 & \\
\hline
\end{tabular}

As shown in Table 4, respondents reported that some of the barriers to their usage of the nets were "the nets were too hot", "it was stressful to spread the nets over the bed before going to bed" and "the nets were uncomfortable.

Table 4: Frequency distribution of Barriers to the Use of Insecticide Treated Nets

\begin{tabular}{|c|c|c|c|}
\hline Variables & Response & Frequency & Percentage \\
\hline \multirow{2}{*}{ The net is too hot } & Yes & 193 & 60.7 \\
\cline { 2 - 4 } & No & 125 & 39.3 \\
\hline \multirow{2}{*}{ It is not comfortable } & Yes & 182 & 57.2 \\
\cline { 2 - 4 } & No & 136 & 42.8 \\
\hline \multirow{2}{*}{$\begin{array}{c}\text { It's stressful to spread before going to } \\
\text { bed }\end{array}$} & Yes & 162 & 50.9 \\
\cline { 2 - 4 } & No & 156 & 49.1 \\
\hline
\end{tabular}

The result in Table 5 revealed that there was a statistical relationship between current usage of the nets and the "net is too hot" $(P=.02)$; "currently using a net" and "It is not comfortable" $(P=.02)$. 
Table 5: Correlation Output for the Relationship between Usage and Barriers to Usage of Insecticide Treated Nets

\begin{tabular}{|c|c|c|c|c|c|}
\hline \multirow[t]{5}{*}{1} & \multirow{2}{*}{ The net is too hot } & \multicolumn{2}{|c|}{$\begin{array}{l}\text { Are you currently using } \\
\text { one? }\end{array}$} & \multirow[b]{2}{*}{ Total } & \multirow{4}{*}{$\begin{array}{c}\begin{array}{c}\mathrm{x}^{2} ; \mathrm{p} \text {-value } \\
(0.05)\end{array} \\
5.126 ; 0.028\end{array}$} \\
\hline & & Yes (\%) & No (\%) & & \\
\hline & Yes & $120(62.2)$ & $73(37.8)$ & $193(100 \%)$ & \\
\hline & No & $93(74.4)$ & $32(25.6)$ & $125(100 \%)$ & \\
\hline & TOTAL & $213(67)$ & $105(33)$ & $318(100 \%)$ & $318(100 \%)$ \\
\hline \multirow[t]{5}{*}{2} & It is not comfortable & \multicolumn{2}{|c|}{$\begin{array}{l}\text { Are you currently using } \\
\text { one? }\end{array}$} & & $\begin{array}{c}\mathrm{x}^{2} ; \mathbf{p} \text {-value } \\
(0.05)\end{array}$ \\
\hline & & Yes (\%) & No (\%) & Total & $5.700 ; 0.022$ \\
\hline & Yes & $112(61.5)$ & $70(38.5)$ & $182(100 \%)$ & \\
\hline & No & $101(74.3)$ & $35(25.7)$ & $136(100 \%)$ & \\
\hline & TOTAL & $213(67.0)$ & $105(33)$ & $318(100 \%)$ & $318(100 \%)$ \\
\hline \multirow[t]{5}{*}{3} & $\begin{array}{l}\text { Its stressful to } \\
\text { spread before }\end{array}$ & \multicolumn{2}{|c|}{$\begin{array}{c}\text { Are you currently using } \\
\text { one? }\end{array}$} & & $\begin{array}{c}\mathrm{x}^{2} ; \mathbf{p} \text {-value } \\
(0.05)\end{array}$ \\
\hline & sleeping & Yes (\%) & No (\%) & Total & $1.727 ; 0.192$ \\
\hline & Yes & $103(63.6)$ & $59(36.4)$ & $162(100 \%)$ & \\
\hline & No & $110(70.5)$ & $46(29.5)$ & $156(100 \%)$ & \\
\hline & TOTAL & $213(67)$ & $105(33)$ & $318(100 \%)$ & $318(100 \%)$ \\
\hline
\end{tabular}

\section{Discussion}

Most of the respondents found at the ante-natal clinics were within 25-29 years age group which falls within the peak reproductive age range. This age range is a representation of the pregnant women in Nigeria as supported by Aluko \& Oluwatosin (2008) and Yusuf, Dada-Adegbola, Ajayi \& Falade (2008) in studies carried out in the same geo-politician zones of Nigeria.

Though the use of ITNs was above average, the goal should be $100 \%$ utilization across all populations. If there is an improved rate of utilization, this would bridge the gap in malaria related morbidities and mortalities recorded in the country. Results from previous studies by Karunamoorthi (2010) and Onwujekwe (2005) also revealed above average levels of use of ITNs. The gap in usage of ITNs could be attributed to ignorance of the importance or unavailability.

The study result also shows that marital status is a determinant of ITN usage. This implies that marriage could increase the use of ITNs in homes. This could be because married caregivers and mothers have better experience and knowledge of child care. Also, social support from husbands could influence net usage. Husbands could remind and encourage the pregnant women to use their nets. Even if the woman is a primigravidae, 
they are more likely to have been exposed to caregiving tips from their families, neighbors or health care providers. Similar results were recorded in studies by Marchant et al. (2002), Gashaw and Wakgari (2008) and Obol, Ononge \& Orach (2013). Also, the finding of the significant association between marital status and use of ITNs was supported by results from previous studies among pregnant women attending antenatal clinics in University of Ilorin Teaching Hospital, Nigeria (Omokanye et al., 2012) and under five children care givers in Ife Central Local Government Area (KGA) of Osun State, Nigeria (Esimai \& Aluko, 2014). Education and age were reported to have no significant relationships with the use of ITNs.

Of importance are the constraint to usage. Respondents reported discomfort when the ITNs are used and some of the factors are "net is too hot", "net is not comfortable" and "net is stressful to spread before sleeping". These constraints have been reported in previous studies (Pullord et al., 2011; Galvin et al., 2011) and they still pose as threats to the rates of maternal and infant mortality. This discomfort could be due to unstable power supply in the country and the typical hot weather in Africa. The use of rechargeable fans and generators overnight are common to Nigerians but the prices and maintenance are quite costly for people of low to middle socioeconomic status. Stable power supply will be effective to sustained use of ITNs among pregnant women.

Continuous health education and sensitization on the use of ITNs as an effective preventive method for malaria during pregnancy should record increased levels of usage. Education about malaria transmission and the benefits of proper use of bed nets should eliminate the misconceptions about bed nets usage. Although discomfort may be experienced with the usage of ITNs, health education centered on the appreciation of the use intervention should continually be done since more than $80 \%$ are currently using one.

Successful control of malaria relies on continued/sustained use of preventive methods such as the ITNs. Some basic aspects of the net design should be adequately examined in future studies. The research study highlights the urgent need for further research on the barriers that have contributed to consistent use of nets by pregnant women, and even after delivery especially in endemic areas such as Nigeria.

\section{Conclusion:}

The present study concludes that the level of usage of ITNs was above average but could still be increased. The coverage of insecticide treated nets needs to be maintained and this will show efforts towards achieving the Millennium Development Goals 4 and 5 which are to reduce child mortality and improve maternal health. Much attention is on access and ownership of ITNs but our results suggest that more effort is needed on 
ensuring sustained usage. There is an evident gap in usage and the barriers pose a threat to sustained use. This is a focal point that public health advocators and communicators should focus on. The observations from this study therefore accentuate the need for more sensitization towards continuous usage of insecticide treated nets.

\section{References:}

1. Clancy, T., Stiner, C., \& Koltz, T. (2002). Shadow warriors: Inside the special forces. New York, NY: Putnam

2. Austin, J. H. (1998). Zen and the brain: Toward an understanding of meditation and consciousness. Cambridge, MA: MIT Press.

3. Calarco, M., \& Atterton, P. (2009). Animal philosophy: Essential readings in continental thought. New York, NY: Continuum.

4. Chen, J. Q. (2003). Intelligence: Multiple intelligences. In J. Guthrie (Ed.),Encyclopedia of education (pp. 1198-1201). New York, NY: Macmillan.

5. Adefioye, O. A., Adeyeba, O. A., Hassan, W. O., Oyeniran, O. A. (2007). Prevalence of malaria parasite infection among pregnant women in Osogbo, southwest Nigeria. American-Eurasian Journal of Scientific Research, 2 (1):43-45.

6. Agomo, C. O. \& Oyibo, W. A. (2013). Factors associated with risk of malaria infection among pregnant women in Lagos, Nigeria. Infectious Diseases of Poverty, 2(19). http://doi.org/10.1186/20499957-2-19.

7. Agomo, C. O., Oyibo, W. A., Anorlu, R.I., Agomo, P.U. (2009). Prevalence of Malaria in Pregnant Women in Lagos, South-West Nigeria. Korean J Parasitol, 47(2):179-183.

8. Aluko, J. O., Oluwatosin, A. O. (2008). Pattern and outcome of antenatal care among women attending a Catholic Mission Hospital in Ibadan, Nigeria. Afri J of Med \& Medical Sci, 37 (3): 231-238.

9. Amoran, O. E., Ariba, A. A., Iyaniwura, C. A. (2012). Determinants of intermittent preventive treatment of malaria during pregnancy (IPTp) utilization in a rural town in Western Nigeria. Reproductive Health, 9(12).

10. Ankomah, A., Adebayo, S. B., Arogundade, E. D., Anyanti, J., Nwokolo, E., Ladipo, O., Meremikwu, M. M. (2012). Determinants of insecticide-treated net ownership and utilization among pregnant women in Nigeria. BMC Public Health, 12:105.

11. Auta, A. (2012). Demographic factors associated with insecticide treated net use among Nigerian women and children. North American Journal of Medical Sciences. 4:40-4. 
12. Clarke, S. E., Bogh, C., Brown, R. C., Pinder, M., Walraven, G. E. L., Lindsay, S. W. (2001). Do untreated bednets protect against malaria? Trans $R$ Soc Trop Med Hyg, 95:457-462.

13. D'Alessandro, U., Olaleye, B., McGuire, W., Langerock, P., Bennett, S., Aikins, M. ... Greenwood, B. M. (1995). Mortality and morbidity from malaria in Gambian children after introduction of an impregnated bed net programme. Lancet, 346:462-467. 10.1016/S0140-6736(95)91321-1.

14. D'Alessandro, U., Olaleye, B.O., McGuir,e W., Thomson, M. C., Landerock, P., Bennett, S., Greenwood, B. M. (1995). A comparison of the efficacy of insecticide-treated and untreated bed nets in preventing malaria in Gambian children. Trans $R$ Soc Trop Med Hyg, 89:596-598.

15. Esimai, O. A. \& Aluko, O. O. (2014). Determinants of Use of Insecticide Treated Bednets Among Caregivers of Under Five Children in an Urban Local Government Area of Osun State, SouthWestern Nigeria. Glob J Health Sci., Mar; 7(2): 20-27.

16. Ezeama, M., Ezeama, F., Akor, Q. (2014). Factors militating against the use of insecticide treated nets among pregnant women in Nigeria. International Journal of Research in Medical and Health Sciences, 4(9):8-14.

17. Galvin, K., Petford, N., Ajose, F., Davies, D. (2011). An exploratory qualitative study on perceptions about mosquito bed nets in the Niger Delta: what are the barriers to sustained use? Journal of Multidisciplinary Healthcare, 4:73-83.

18. Gashaw, D., Wakgari, D. (2008). Knowledge and Utilisation of insecticide treated mosquito nets among freely supplied households in Wonago Woreda, Southern Ethiopia. Ethiop J Health Dev., 22:3441.

19. Hawley, W. A., ter Kuile, F. O., Steketee, R. S., Nahlen, B. L., Terlouw, D. J., Gimnig, J. E. ... Phillips-Howard, P. A. (2003). Implications of the western Kenya permethrin-treated bed net study for policy, program implementation, and future research. Am J Trop Med Hyg., 4:168-173.

20. Hill, J., Hoyt, J., van Eijk, A. M,. D'Mello-Guyett, L., ter Kuile, F.O., Steketee, R. et al. (2013). Factors Affecting the Delivery, Access, and Use of Interventions to Prevent Malaria in Pregnancy in Sub-Saharan Africa: A Systematic Review and Meta-Analysis. PLoS Med. 10(7):e1001488. doi:10.1371/journal.pmed.1001488.

21. Huailu, C., Wen, Y., Wuanmin, K., Chongyi, L. (1995). Large-scale spraying of bed nets to control mosquito vectors and malaria in Sichuan, China. Bull World Health Organ. 73:321-328. 
22. Kalu, K. M., Obasi, N. A., Nduka, F. O., Otuchristian, G. (2012). A Comparative Study of the Prevalence of Malaria in Aba and Umuahia Urban Areas of Abia State, Nigeria. Research Journal of Parasitology, 7:17-24.

23. Karunamoorthi, K., Deboch, B., Tafere, Y. (2010). Knowledge and practice concerning malaria, insecticide-treated net (ITN) utilization and antimalarial treatment among pregnant women attending specialist antenatal clinics. Journal of Public Health, 18(6):559.

24. Lengeler, C. (2004). Insecticide-treated net bed net and curtains for preventing malaria. Cochrane Database Syst Rev 2:CD000363.

25. Marchant, T., Schellenberg, J. A., Edgar, T., Natha, R., Abdulla, S., Mukasa, O. ... Lengeler, C. (2002). Socially marketed insecticidetreated nets improve malaria and anaemia in pregnancy in southern Tanzania. Tropical Medicine and International Health. 7:149-158.

26. National Malaria Control Programme, Nigeria. (2008). Annual Report.

27. Obinna, C. (2011). Malaria: A pregnant woman's worst enemy. FCT, Abuja. Vanguard News. Accessed on February 21, 2016

28. Obol, J. H., Ononge, S., Orach, C. G. (2013). Utilisation of insecticide treated nets among pregnant women in Gulu: a post conflict district in northern Uganda. Afr Health Sci. Dec; 13(4): 962969. doi: 10.4314/ahs.v13i4.15

29. Oche, M. O., Ameh, I. G., Umar, A. S., Gana, G., Njoku, C. H. (2010). Awareness and the use of Insecticide Treated Net (ITN) among pregnant women attending ante-natal at Usmanu Danfodiyo University Teaching Hospital, Sokoto. Nigerian Journal of Parasitology, 31(2).

30. Omokanye, L. O., Saidu, R., Olatinwo, A. W., Jimoh, A. G, Saludeen A. G, Balogun O. R, Panti A. A. (2012). The Determinants of Utilization of Insecticide Treated Nets Among Pregnant Women Attending Antenatal Clinic at University of Ilorin Teaching Hospital, Ilorin, Nigeria. Int J Biol Med Res. 3(4):2538-2541.

31. Onwujekwe, O., Uzochukwu, B., Ezumah, N., Shu, E. (2005). Increasing coverage of insecticide-treated nets in rural Nigeria: implications of consumer knowledge, preferences and expenditures for malaria prevention. Malaria Journal, 4:29. DOI: 10.1186/14752875-4-29.

32. Pulford, J., Hetzel, M. W., Bryant, M., Siba, P. M., Mueller, I. (2011). Reported reasons for not using a mosquito net when one is available: a review of the published literature. Malaria Journal, $10: 83$. 
33. Roll Back Malaria (RBM). (2010). Insecticide treated Mosquito nets WHO 2001-2010.

34. Singh, M., Brown, G. and Rogerson, S.J. (2013). Ownership and use of insecticide-treated nets during pregnancy in sub-Saharan Africa: a review. Malaria Journal, 12:268

35. Wogu, M. N. \& Nduka, F.O. (2013). Effectiveness and Compliance of Long Lasting Insecticide Nets on Malaria Parasitemia among Pregnant Women attending Ante-natal Clinics in Port Harcourt Rivers State. British Journal of Medicine \& Medical Research, 12331239.

36. World Health Organization. (2010). World Health Organization Global Malaria Programme: Position Statement on ITNs.

37. World Health Organization. (2008). World Malaria Report, Switzerland: World Health Organization.

38. Yusuf, O. B., Dada-Adegbola, H. O., Ajayi, I. O., Falade, C. O. (2008). Malaria prevention practices among mothers delivering in an Urban hospital in southwest Nigeria. J Vector Borne Dis., 45: 217224. 